\title{
Development of a Diverse Learning Experience for Diverse Psychiatry Resident Needs: A Four-Year Biological Psychiatry Curriculum Incorporating Principles of Neurobiology, Psychopharmacology, and Evidence-Based Practice
}

\author{
Andrew J. Muzyk ${ }^{1,2} \otimes$, Jane P. Gagliardi ${ }^{2,3}$, Gopalkumar Rakesh², Michael R. Jiroutek ${ }^{4}$, \\ Rajiv Radhakrishnan ${ }^{5}$, Chi-Un Pae ${ }^{2,6}$, Prakash S. Masand ${ }^{7,8}$, and Steven T. Szabo ${ }^{2,9}$ \\ ${ }^{1}$ Department of Pharmacy Practice, Campbell University School of Pharmacy and Health Sciences, Buies Creek, NC, USA \\ ${ }^{2}$ Department of Psychiatry \& Behavioral Sciences, Duke University, Durham, NC, USA \\ ${ }^{3}$ Department of Medicine, Duke University, Durham, NC, USA \\ ${ }^{4}$ Department of Clinical Research, Campbell University College of Pharmacy \& Health Sciences, Buies Creek, NC, USA \\ ${ }^{5}$ Department of Psychiatry, Yale University Health System, New Haven, CT, USA \\ ${ }^{6}$ Department of Psychiatry, The Catholic University of Korea College of Medicine, Seoul, Korea \\ ${ }^{7}$ Academic Medicine Education Institute, Duke-NUS Medical School, Singapore \\ ${ }^{8}$ Global Medical Education, New York, NY, USA \\ ${ }^{9}$ Mental Health Service Line, Veterans Affairs Medical Center, Durham, NC, USA
}

Objective A clinically relevant approach to patient care grounded in neurobiological constructs and evidence based practice which emphasizes a relevant psychopharmacology is needed to optimally train psychiatry residents.

Methods We implemented a biological psychiatry course that now incorporates neurobiology, psychopharmacology, and evidencebased practice in conjunction with a Research Domain Criteria $(\mathrm{RDoC})$ perspective. A survey launched prior to course implementation and following each class session, served as the outcome metric of residents' attitudes toward the new curriculum and followed a baseline attitudinal survey designed to evaluate the program.

Results Greater than $90 \%$ of the psychiatry residents at Duke University who took the attitudinal survey agreed or strongly agreed with needing a course that helped them develop an understanding of neurobiology, psychopharmacology, and evidence-based practice concepts. Most residents also indicated a less than adequate understanding of the neurobiology and psychopharmacology of psychiatric disorders prior to sessions.

Conclusion Our biological psychiatry curriculum was associated with enthusiasm among residents regarding the incorporation of neurobiology, psychopharmacology, and evidence-based practice into course topics and discussions. A biological psychiatry curriculum with integrated neurobiology and psychopharmacology built on an evidence base approach is possible, well-received, and needed in training of future psychiatrists.

Psychiatry Investig 2017;14(3):289-297

Key Words Neurobiology, Psychopharmacology, Evidence-based practice, Resident education, Pedagogy, Active learning.

\section{INTRODUCTION}

Over the last few years, the field of psychiatry has attempted

Received: March 15, 2016 Revised: March 15, 2016

Accepted: June 3, 2016 Available online: February 27, 2017

$\triangle$ Correspondence: Andrew Muzyk, PharmD

Department of Psychiatry \& Behavioral Sciences, Duke University, Durham, NC 27713, USA

Tel: +1-919-681-3438, E-mail: Andrew.Muzyk@duke.edu

(a) This is an Open Access article distributed under the terms of the Creative Commons Attribution Non-Commercial License (http://creativecommons.org/licenses/bync/4.0) which permits unrestricted non-commercial use, distribution, and reproduction in any medium, provided the original work is properly cited. to decipher neurobiological constructs in psychiatric illnesses. ${ }^{1}$ Advancements in brain imaging have been instrumental to understanding the neurobiology of disease and treatment response in disorders of depression, psychosis, dementia, and addiction..$^{2-8}$ Techniques such as functional near infra-red spectroscopy, ${ }^{9}$ optogenetics ${ }^{10}$ and CLARITY ${ }^{11,12}$ have opened up new frontiers for studying and manipulating brain circuits on a fundamental basis and also makes possible neurobiological clinical translation in patients suffering with psychiatry illness. Core concepts of neuroplasticity, pluripotent stem cells, epigenetics, and device driven neuromodulation 
using transcranial magnetic stimulation (TMS) and direct electrical current stimulation (tDCS) are at the root of progress in neurosciences. In order to remain relevant in science and to optimally translate research findings into clinical practice, psychiatrists increasingly need a conceptual appreciation of these neurobiological advancements in psychiatric illness. Evolving concepts of salience, cognitive control, emotional processing, social cognition, reward responsiveness and cognitive processes such as working memory as it pertains to psychiatric disorders need to be disseminated. Integration of new scientific discoveries into the current DSM-5 phenomenological classification systems will require time. ${ }^{13}$ However, the latency for integration should not be a barrier to clinical application or dissemination of these concepts to psychiatric trainees or providers.

Psychiatry residents are required to learn the pharmacology of psychotropic medications; just as importantly, trainees need to learn how to use the current evidence base to support rational treatment decisions. ${ }^{14-19}$ In addition to recognizing validity and methodology of scientific publications, trainees also need to have solid foundational knowledge regarding neurobiological processes in order to understand and consume the rapidly expanding body of literature for becoming a life-long learner. ${ }^{16,17,20-23}$ While recent psychiatry residency education studies have highlighted the need for education in core areas of neuroscience and psychopharmacology, there is no profession-wide consensus on the best methods for imparting this knowledge onto residents. ${ }^{24-26}$

The American Board of Psychiatry and Neurology/Accreditation Council for Graduate Medical Education (ABPN/ACGME) Milestone Project has incorporated milestones to measure training in neuroscience, psychopharmacology, and the incorporation of evidence-based practice into these two content areas. ${ }^{27,28}$ Neurobiologyis included in Medical Knowledge milestones such as MK-A3, which encompasses knowledge on neurobiological and genetic hypotheses of psychiatric disorders, identification of brain areas involved in social behavior and emotions, use of investigation techniques such as imaging,as well as incorporation of neuroscientific hypotheses into case formulations are to be key priorities. Patient Care milestones (i.e., PC-A3 and PC-A5) are designed to assess the trainee's ability for treatment planning and management and the pharmacology and therapeutic use of psychotropic. ${ }^{24}$ In addition to addressing the developmental skills recognized as necessary in neurobiology, a contemporary curriculum should incorporate RDoC's cognitive neuroscience dimensions. ${ }^{29-34}$ Finally, in order to be successful, graduate medical education opportunities should optimally strive for being built on the principles of the adult learning theory. ${ }^{19,34,35} \mathrm{~A}$ recent study found a prevalence of depressive symptoms among resident physicians globally to be $30 \%{ }^{36}$ This calls for learning programs designed using adult learning theory and hence empowering learners while they learn.

Adult learning theory predicts better outcomes with active learning, and psychiatry residency programs that have moved away from didactic lectures to active educational exercises have demonstrated increased success and resident satisfaction. ${ }^{15,17-19,22,37}$ Engaging residents as teachers improves the resident-teacher's clinical knowledge, skills, and self-directed learning techniques, all likely important to clinician competence. ${ }^{38}$

While keeping in mind the need for emphasizing the realtime integration of the best neuroscientific and psychopharmacological evidence, and with a goal of promoting active learning among residents, we developed a four-year biological psychiatry (BIOPSY) curriculum for the Duke University Hospital Psychiatry Residency training program.

\section{METHODS}

\section{Program development and background}

Since 2003, the Duke University Hospital Psychiatry Residency Training Program has protected a half-day per week for residents in all years of training, and the Biological Psychiatry (BIOPSY) course has been a cornerstone of the curriculum since then. In keeping with the training program's dedication to continuous programmatic assessment and improvement, the BIOPSY course is constantly evolving; changes have occurred over time in response to updates in ACGME requirements, the psychiatry milestones, scientific advancements, educational theories on learner behavior, and especially in response to feedback from resident exit interviews revealing mastery of core concepts and skills taught in BIOPSY is critical to their development. The curriculum has constantly evolved iteratively from year to year with a greater emphasis on psychopharmacology starting in 2011. Resident-led active learning and evidence based practice discussions were incorporated in 2012, and the addition of sessions aimed at neurobiology was introduced in the 2013-2014 academic year. For the 2014-2015 academic year, all of the aforementioned changes as well as multiple newly chosen topics were incorporated into the current four-year comprehensive curriculum.

\section{Curriculum design}

In its current form, the BIOPSY curriculum comprises three year-long courses for three separate resident groups: PGY1 residents, PGY2-PGY3 residents, and PGY4 residents. The class sessions occur on Thursday mornings for 80 minutes. There are approximately 33 weeks total for BIOPSY classes during a given year. Given various combined sessions between 
classes, the course masters plan 55 unique class sessions annually. Nineteen class sessions include the entire residency program (all four years), 4 class sessions include only the PGY1s and PGY4s, and 1 class session includes the PGY2s, PGY3s, and PGY4s. The goal of the mixed resident sessions is to help foster interaction and teaching between residents. Group-specific class sessions also allow for targeted education topics to be given that is based on the resident group's current level of knowledge and clinical experience. Regardless of the topics being covered, residents are expected to come to class prepared to engage in the discussion and presenters were asked to make their classes interactive. Readings are assigned via email one-week prior to class which is maintained on a secure educational website.

The majority of the class sessions throughout the general psychiatry curriculum (approximately 5-8 sessions per each topic) pertain to five main clinical topics: schizophrenia, mood disorders, anxiety spectrum disorders, cognitive disorders, and addictions. Topics with less class time (3 sessions per each topic) include: sleep disorders, delirium, catatonia, toxidromes, personality disorders, and neurological disorders. Topics not covered during one academic year are included in the next year, such that curriculum topics repeat every 18-24 months. For example, in the 2014-2015 calendar year the PGY2-PGY3 course covered only two main topics, cognitive disorders and anxiety spectrum disorders, while the 2015-2016 year will include schizophrenia, mood disorders, and addictions.

\section{Curriculum committee and selection of topics}

Authors SS and AM are co-course masters for BIOPSY and maintain responsibility for determining the selection of topics, scheduling of sessions, and identification of relevant literature and topic content experts. Supplementary Table 1 (in the online-only Data Supplement) includes the 2014-2015 BIOPSY course calendars. The course for PGY1 residents is organized into "boot camps" centered on topics overviewing core brain anatomy, neurobiology, psychopharmacology, and treatment guidelines. Pivotal psychiatry trials including CATIE, CUTLASS and STAR*D provide a strong foundational knowledge base on the fundamentals of neurobiology of psychiatric disorders, pharmacology of psychotropic medications, recognition and management of adverse effects, and the relevance of this to clinical trial outcomes and treatment guidelines.

The PGY2-PGY3 course is designed to expand on the knowledge gained during the BIOPSY courses in the PGY1 year and knowledge gained during clinical rotations to facilitate a deepening of residents' understanding of the neurobiology and treatment of psychiatric illness. Residents are taught to engage with the evidence base to support informed clinical decisions. The PGY2-PGY3 course is essentially designed with separate modules for each psychiatric disorder. For instance, one session within a module focuses on a non-scientific paper (NY Times, New Yorker), two to three sessions cover neurobiology and assessment, and three to four sessions cover psychopharmacology. Topics in this course repeat every two years with expert faculty members serving as both facilitators and presenters to help course masters identify relevant articles for discussion.

The course for the PGY4+ residents was developed from results using a "learning needs assessment" from senior residents that were eager to prepare for their post-residency careers and motivated to solidify good habits for lifelong learning and evidence-based practice during their final years of training. The PGY4+ course focuses exclusively on the real-time use of evidence-based practice in the clinic with discussions geared towards the "clinical pearls" of practice. Residents gain a deeper understanding of how to pose a clinical question, obtain appropriate articles, and appraise recent publications in the relevant literature base.

Feedback from graduates of the residency program has been used to prepare topics covered in all years from PGY1-4. The inclusion of "boot camps on neuroanatomy" was done based on such feedback given by graduates. Efforts have also been made to focus on psychopharmacology and neurobiology principles that can be used by trainees in daily clinical practice. Some additional topics that evolved from this feedback are weaning benzodiazepine dependent people off them, understanding neurobiology of stimulant action, principles of medication adherence and compliance, management of pain medication dosing and management of dementia. When examined broadly these are all practical and relevant topics that are encountered in daily practice, the relevant neurobiological mechanisms and evidence base is instrumental in forming foundational knowledge that trainees will need following residency training in psychiatry. Prevalence rates dictate that a large portion of dementia and schizophrenia patients are seen in outpatient or inpatient practices, thus a detailed understanding of neurobiology of schizophrenia including discussions on cognitive deficits, working memory challenges, and social cognition becomes extremely relevant. The neurobiology of posttraumatic stress disorder, anxiety disorders, mood disorders, and addiction, including that of suicide, are incorporated in generating discussions on relevant research literature using animal models and emotional processing tools for greater understanding of the psychopharmacologic bases of drug effects in these disorders. Critical appraisal of literature such as clinical drug trials requires exposure to discussions on evaluations on RCTs, systematic reviews and meta-analyses. On the whole the curriculum makes an attempt to cover topics in line with $\mathrm{RDoC}$ in featuring broad do- 
mains of reward, perception, sleep-wakefulness, social processes, and cognitive processes.

\section{Curriculum topics, presenters, and technology}

Several online application tools were used to help course masters identify curriculum topics with presenters, provide access to literature, and to bring presenters into the classroom via video conference when necessary. The relevant literature for chosen topics are gleaned from a variety of places including: online resources such as articles found in PubMed, treatment guidelines from the American Association of Psychiatry, chapters from the Textbook of Psychopharmacology, and articles in the New Yorker and New York Times.

Presenters come from a diverse group of talented and multidisciplinary individuals; they are recruited from both within and outside Duke University School of Medicine. There are approximately 42 unique presenters per course year. Presenters in 2014-2015 came from four different departments within the Duke School of Medicine and from 11 different institutions outside of Duke. Presenters usually are identified based on their expertise or reputation in a topic area. Skype is used to bring in presenters outside of Duke to lead class discus- sions for both resident-group specific and all-resident sessions. The use of Skype allows course masters to bring in leading experts, creates a greater variety of presenters, and gives the residents an opportunity to learn others' (non-Duke faculty) perspectives and to learn about clinical practice in another part of the United States or in another country. Practicing clinicians from the counties surrounding our institution also can be brought in to discuss "real-world" (non-academic) practice related issues. Presenters are strongly encouraged to use the majority of time to engage the residents in active learning (such as group case work, reflection, and posing challenging clinical questions) and classroom discussions.

\section{Assessment}

The protocol used to assess the effectiveness of the BIOPSY curriculum was submitted for review by the Duke University Hospital Investigation Review Board (IRB) and determined to be exempt as an investigation of an educational intervention. No protected health information or personal identifiers were maintained in any of the data used for the assessment.

At the beginning of the academic year a 30-question survey (with questions about demographics, career plans, and

Table 1. Residents' responses to demographic questions in the pre-curriculum survey

\begin{tabular}{|c|c|}
\hline Question & $\mathrm{N}(\%)$ \\
\hline Total number of respondents, $\mathrm{N}$ (\% out of 51 total residents) & $38(75)$ \\
\hline \multicolumn{2}{|l|}{ Current level of training } \\
\hline First year & $13(34)$ \\
\hline Second year & $7(18)$ \\
\hline Third year & $9(24)$ \\
\hline Fourth year & $8(21)$ \\
\hline Fifth year & $1(3)$ \\
\hline \multicolumn{2}{|l|}{ What is your current program } \\
\hline Psychiatry & $32(84)$ \\
\hline Medicine-psychiatry & $6(16)$ \\
\hline \multicolumn{2}{|l|}{ Do you have an advanced degree (in addition to MD) } \\
\hline Masters' & $8(21)$ \\
\hline $\mathrm{PhD}$ or equivalent & $2(5)$ \\
\hline Other advanced degree & $2(5)$ \\
\hline None & $26(68)$ \\
\hline \multicolumn{2}{|c|}{ What do you anticipate your approximate scope of clinical practice will be following residency training } \\
\hline Private practice clinician, medication management only & $2(5)$ \\
\hline Private practice clinician, including psychotherapy & $4(11)$ \\
\hline Academic, clinician educator & $12(32)$ \\
\hline Academic, clinical researcher & $5(13)$ \\
\hline Academic, basic science researcher & $1(3)$ \\
\hline Community psychiatry, public sector & $4(11)$ \\
\hline Other & $10(26)$ \\
\hline
\end{tabular}


Table 2. Residents' responses to "attitudinal" questions in the pre-curriculum survey

\begin{tabular}{|c|c|}
\hline Question & $\begin{array}{l}\text { Percentage of responders }>3 \\
\qquad(\mathrm{~N}=38) \\
\text { mean } \pm \mathrm{SD} \text {; median }\end{array}$ \\
\hline \multicolumn{2}{|l|}{ Residents' attitudes toward questions about core content of curriculum } \\
\hline Rate your understanding of psychopharmacology of psychiatric disorders* & $\begin{array}{c}5.3 \% \\
2.5 \pm 0.7 ; 2.5\end{array}$ \\
\hline Rate your understanding of neurobiology of psychiatric disorders* & $\begin{array}{c}0.0 \% \\
2.1 \pm 0.6 ; 2.0\end{array}$ \\
\hline In my clinical activities, I feel confident explaining the psychopharmacology of psychiatric disorders ${ }^{\dagger}$ & $\begin{array}{c}42.0 \% \\
3.1 \pm 0.9 ; 3.0\end{array}$ \\
\hline In my clinical activities, I feel confident explaining the neurobiology of psychiatric disorders ${ }^{\dagger}$ & $\begin{array}{c}7.0 \% \\
2.6 \pm 0.9 ; 2.0\end{array}$ \\
\hline Having a strong understanding of psychopharmacology would be useful to me in my clinical activities ${ }^{\dagger}$ & $\begin{array}{c}91.8 \% \\
4.6 \pm 0.8 ; 5.0\end{array}$ \\
\hline Having a strong understanding of neurobiology would be useful to me in my clinical activities ${ }^{\dagger}$ & $\begin{array}{c}81.6 \% \\
4.1 \pm 0.9 ; 4.0\end{array}$ \\
\hline $\begin{array}{l}\text { I need a course that helped me develop my evidence-based medicine skills (i.e., to better understand and } \\
\text { analyze literature })^{\dagger}\end{array}$ & $\begin{array}{c}55.3 \% \\
3.6 \pm 0.9 ; 4.0\end{array}$ \\
\hline I need a course that helped me develop my understanding of psychopharmacology ${ }^{\dagger}$ & $\begin{array}{c}92.1 \% \\
4.3 \pm 0.8 ; 4.0\end{array}$ \\
\hline I need a course that helped me develop my understanding of neurobiology ${ }^{\dagger}$ & $\begin{array}{c}97.4 \% \\
4.4 \pm 0.8 ; 4.0\end{array}$ \\
\hline $\begin{array}{l}\text { I am confident when speaking with my patients about the basic psychopharmacology of their } \\
\text { psychotropic medications }{ }^{\dagger}\end{array}$ & $\begin{array}{c}60.5 \% \\
3.4 \pm 0.9 ; 4.0\end{array}$ \\
\hline I am confident when speaking with my patients about the basic neurobiology of their psychiatric disorders ${ }^{\dagger}$ & $\begin{array}{c}34.2 \% \\
2.9 \pm 0.9 ; 3.0\end{array}$ \\
\hline $\begin{array}{l}\text { A course that provide learning in psychopharmacology would enhance my understanding of topics } \\
\text { presented in other learning opportunities (i.e., Chair's Rounds, Department of Psychiatry Grand } \\
\text { Rounds, etc. })^{\dagger}\end{array}$ & $\begin{array}{c}89.5 \% \\
4.1 \pm 0.7 ; 4.0\end{array}$ \\
\hline $\begin{array}{l}\text { A course that provide learning in neurobiology would enhance my understanding of topics presented } \\
\text { in other learning opportunities (i.e., Chair's Rounds, Department of Psychiatry Grand Rounds, etc.) }{ }^{\dagger}\end{array}$ & $\begin{array}{c}89.5 \% \\
4.1 \pm 0.7 ; 4.0\end{array}$ \\
\hline \multicolumn{2}{|l|}{ Residents' attitudes towardquestions about the pedagogical approach of curriculum } \\
\hline $\begin{array}{l}\text { A course where I am asked to give multiple presentations would improve my comfort level with presenting } \\
\text { in front of an audience }{ }^{\dagger}\end{array}$ & $\begin{array}{c}39.5 \% \\
3.1 \pm 0.9 ; 3.0\end{array}$ \\
\hline $\begin{array}{l}\text { A course where I am asked to give multiple presentations would improve my comfort level discussing } \\
\text { issues with my patients }{ }^{\dagger}\end{array}$ & $\begin{array}{c}44.7 \% \\
3.1 \pm 1.1 ; 3.0\end{array}$ \\
\hline I would miss out on learning if class time was not used for a didactic lecture by a faculty expert ${ }^{\dagger}$ & $\begin{array}{c}44.7 \% \\
3.3 \pm 1.1 ; 3.0\end{array}$ \\
\hline $\begin{array}{l}\text { I learn best from a class that uses active learning exercises to allow for participation from me and } \\
\text { my fellow residents }{ }^{\dagger}\end{array}$ & $\begin{array}{c}60.5 \% \\
3.5 \pm 1.1 ; 3.0\end{array}$ \\
\hline Psychopharmacology topics are too complex to be taught by residents ${ }^{\dagger}$ & $\begin{array}{c}5.3 \% \\
2.4 \pm 0.8 ; 2.0\end{array}$ \\
\hline Neurobiological topics are too complex to be taught by residents ${ }^{\dagger}$ & $\begin{array}{c}23.7 \% \\
2.8 \pm 1.0 ; 3.0\end{array}$ \\
\hline I am mostly a passive learner ${ }^{\dagger}$ & $\begin{array}{c}15.8 \% \\
2.5 \pm 1.0 ; 2.0\end{array}$ \\
\hline If asked to participate in a class discussion I would feel comfortable doing $\mathrm{so}^{\dagger}$ & $\begin{array}{c}68.4 \% \\
3.8 \pm 1.0 ; 4.0\end{array}$ \\
\hline
\end{tabular}


Table 2. Residents' responses to "attitudinal" questions in the pre-curriculum survey (continued)

\begin{tabular}{|c|c|}
\hline Question & $\begin{array}{c}\text { Percentage of responders }>3 \\
(\mathrm{~N}=38) \\
\text { mean } \pm \mathrm{SD} \text {; median }\end{array}$ \\
\hline I would welcome the opportunity to contribute to a discussion on a psychiatry topic ${ }^{\dagger}$ & $\begin{array}{c}73.7 \% \\
3.9 \pm 0.9 ; 4.0\end{array}$ \\
\hline I am too busy to prepare a topic presentation for class ${ }^{\dagger}$ & $\begin{array}{c}47.4 \% \\
3.3 \pm 1.1 ; 3.0\end{array}$ \\
\hline $\begin{array}{l}\text { As a resident presenter, I would feel responsible for making sure that other residents learn from } \\
\text { my presentation }{ }^{\dagger}\end{array}$ & $\begin{array}{c}89.5 \% \\
4.1 \pm 0.7 ; 4.0\end{array}$ \\
\hline $\begin{array}{l}\text { It is my responsibility to teach myself or to teach my fellow residents in a classroom setting (i.e., outside } \\
\text { of your clinical activites) }{ }^{\dagger}\end{array}$ & $\begin{array}{c}71.1 \% \\
3.7 \pm 0.8 ; 4.0\end{array}$ \\
\hline
\end{tabular}

*likert-type scale with 1 inadequate; 2 less than adequate; 3 adequate; 4 more than adequate, 5 excellent, tlikert-type scale with 1 strongly disagree; 2 disagree; 3 neither agree nor disagree; 4 agree, 5 strongly agree

Table 3. Responses to weekly class session evaluations

\begin{tabular}{lc}
\hline \multicolumn{1}{c}{ Question } & $\begin{array}{c}\text { Percentage of responders } \geq 3 \\
\text { mean } \pm \text { SD; median }\end{array}$ \\
\hline Residents' evaluation of weekly class sessions $(\mathrm{N}=137)$ & $90.4 \%$ \\
I would feel confident communicating the information I learned today to my treatment team, colleagues & $3.0 \pm 0.5 ; 3.0$ \\
and patients* & $40.1 \%$ \\
Prior to the class session today, how would you rate your understanding of the topic ${ }^{\dagger}$ & $2.4 \pm 0.9 ; 2.0$ \\
& $85.4 \%$ \\
Now that the class session is over, please rate your understanding of the topic ${ }^{\dagger}$ & $3.2 \pm 0.7 ; 3.0$ \\
& $75.2 \%$ \\
If today's class allowed for an open discussion (i.e. was NOT a lecture alone), how would you rate your & $3.1 \pm 0.9 ; 3.0$ \\
participation & \\
Overall, I would rate today's class as ${ }^{\dagger}$ & $83.2 \%$ \\
\end{tabular}

*likert-type scale with 1 strongly disagree; 2 disagree; 3 agree, 4 strongly agree, tlikert-type scale with 1 poor; 2 fair; 3 good; 4 very good, 5 excellent

goals and attitudes toward the curriculum) was administered. The "attitudinal" portion of the survey included 25 questions and was created by the study authors from similarly worded questionnaires published in educational research articles. The survey was administered yearly to assess for any changes in residents' attitudes toward the curriculum content or pedagogical approach. Residents and presenters were asked to complete weekly class evaluations to gauge their opinions toward each individual class session. Finally, the Duke Psychiatry Residency curriculum oversight committee, which meets monthly to discuss every course within the academic half day, provided feedback on the progress of each course.

\section{Statistical analysis}

All personally identifiable information was removed from measures prior to analysis. Summary statistics were conducted to assess survey data and quiz scores. Statistical analysis was performed using SAS ${ }^{\circledR}$, version 9.3 (SAS Institute, Cary, NC, USA).

\section{RESULTS}

\section{Pre-curriculum assessments}

\section{Attitudinal survey}

Thirty-eight out of 51 residents (75\%) completed the attitudinal survey. Division of residents by year of training is 13 , $7,9,8,1$ in the first, second, third, fourth and fifth years of training. There are 32 residents from categorical psychiatry residency and 6 from the combined medicine-psychiatry residency program. Among participants, 12 out of 38 residents (31.6\%) had advanced academic degree. A large portion of residents who took the survey (10) anticipated becoming academic educators and 6 of them anticipated going into private practice. Table 1 contains residents' responses to demographic questions, while their responses to attitudinal questions are found in Table 2. Greater than $90 \%$ of the psychiatry residents at Duke University taking the attitudinal survey agreed or strongly agreed with needing a course that helped them 
develop an understanding of neurobiology, psychopharmacology, and evidence-based practice concepts. Most residents also indicated a less than adequate understanding of the neurobiology and psychopharmacology of psychiatric disorders. Residents agreed or strongly agreed with statements supporting an active-learning approach to classroom learning, feeling responsible for their own learning and for their fellow residents' learning, and volunteering to contribute to a classroom discussion.

\section{Weekly resident class evaluations}

Residents completed a five question assessment with Likerttype responses for each weekly class session. A total of 137 evaluations were completed. Overall, following class completion, residents reported an increase in their level of understanding of a topic and felt confident communicating what they learned to others. The majority of residents indicated a high level of participation in classroom discussions and rated the class sessions from good to excellent. Table 3 contains residents' responses to these questions. Nearly $90 \%$ of residents felt they could communicate to the information they learnt to their colleagues, to patients and their relatives after the class. $85 \%$ felt they understood the topic much better after class.

\section{DISCUSSION}

We report successful implementation into a four-year psychiatry resident training curriculum that integrates core concepts of neurobiology, psychopharmacology, and evidencebased practice while also imparting skills that are essential to critical thinking and lifelong learning. Additionally, active learning pedagogy and use of varied online application tools facilitated the development of highly interactive class sessions, bringingcutting-edge research and world-renowned researchers and clinicians into the classroom, allowing presenters to share their expertise and experience. Based on findings from pre-curriculum attitudinal surveys, the topic areas covered in this curriculum are in-line with residents' self-identified learning deficits, while weekly post-class evaluations demonstrate the ability of residents to participate in their learning. The residents indicated that this trainingexperiencelead to an increase in their knowledge of topics, felt confident communicating what they learn to others, and highly rated the class sessions.

The gaps in implementation of an up-to-date psychopharmacology curriculum have been emphasized in educational literature. Specific concerns and limitations of traditional pedagogy include the inability of fixed syllabuses to address rapidly expanding concepts, which is essential for preparing the next generation of psychiatrists, in topics such as pharmacogenomics, precision medicine, and psychopharmacology. ${ }^{39-42} \mathrm{~A}$ survey of psychiatry chief residents revealed that nearly $80 \%$ did not feel that their training program prepared them for translating future neuroscience research findings into clinical practice, and the majority of respondents reported inadequate preparation to engage in discussions or research using RDOC. ${ }^{43}$ Challenges to neuroscience education additionally centers on difficulties identifying a foundational curriculum and faculty experts to convey essential principles. ${ }^{44}$ When surveyed, psychiatry department chairs across the country showed support for topics such as neural circuitry, emotional regulation, basic pharmacology, developmental neurobiology, reward systems, perceptual systems, and genetics. ${ }^{45}$ The National Neuroscience Curriculum Initiative (NNCI), developed through collaboration between professional societies in 2014, provides online video resources that detail neuroscience formulations in psychiatric disorders which is presented by experts in the field. ${ }^{21}$

When designing our program, we took into consideration and expanded on principles employed in recent documented educational program developments ${ }^{22,46}$ by including not only neurobiology and psychopharmacology but alsoemphasizing real-time application of their best evidence. We also worked to factor clinical relevance throughout our revised curriculum in order to incorporate feedback from alumni. In our institution, faculty are expected to provide a certain amount of "teaching" per year, and participation in the BIOPSY course helps faculty members meet the teaching expectation. Fortunately, faculty at our institution also were willing to abandon traditional didactic methodology in favor of more active learning strategies and incorporating neurobiology, psychopharmacology, and $\mathrm{RDoC}$ frameworks. In cases in which local faculty were not able to provide expertise on specific topics, experts were brought in through skype presentations.

Implementation of the BIOPSY curriculum required a few key elements to be successful, including protected time during training in which all four years of residents are available at the same time; faculty who are willing to facilitate sessions as "expert discussants" rather than didactic lecturers; residents who are able to prepare and facilitate discussions during some of the sessions; and protected time to permit course codirectors to plan and implement the course.

Course co-directors received a token of compensation for their participation in the course, though much of the overall effort is voluntary or in-kind. Over the years the course has achieved the best results when resident champions were engaged, involved, and proactive in terms of facilitating resident participation and helping to identify relevant topics and speakers.

Other key features to the success of the course include 1) relevance of topic discussions to clinical practice, maintaining 
clinical relevance, 2) engagement of the residents through active-learning teaching approaches, 3) encouraging residents to come prepared to discuss to the topic (and providing timely reminders with easy access to assigned readings), and 4) allowing presenters to facilitate resident discussion and share their clinical experience and content expertise.

It is recognized that the curricula from one institution, such as what we have developed, may be difficult to pick up and adapt "as-is" in another academic setting. However, the approach to incorporating discovery neurobiology, pharmacology, and evidence-based medicine principles into a foundational course designed to optimize active learning opportunities and provide trainees an ability to teach and further their own skills is one that other programs could adapt based on their own strengths and resources.

Future evaluation of the course might include strategies that incorporate comparative Psychiatry Residency In-Training Examination (PRITE) scores over time, end-of-year assessment of core concepts, or other measures of trainee performance (including, for instance, achievement of milestones within the core competency of Medical Knowledge), and post-graduate surveys. We anticipate continued evolution and improvement of the BIOPSY course we have detailed in this publication, which has become a cornerstone of a rich and integrated curriculum at Duke University.

Finally, psychiatry residency program may be different among individual country based on cultural background. It could be also influenced by the modification of training policy by government. For example, Korean government announcedto start the new residency program and thereby postgraduate medical students had to encounter the new residency training programwithout the internship from 2015. Anationwide survey for teaching psychiatrists and psychiatry residents who just finished the PsychiatryBoard Examination in 2013 was designed and conducted by the Korean Neuropsychiatric Association to ask the expected problems thatmight occur if the internship program were abolished, and some significant issues regarding residentrotation schedule to other departments. According to results, most responders felt the importance of psychosomatic medicine, neurology and internal medicine, emergency medicine, in particular, during 1 st and 2 nd year resident periods. It should be more hands-on clinical training through broad-based clinical exposure than Duke Psychiatry. This discrepancy may indicate that the need of psychiatry trainees may be also influenced and changed by diverse educational, social and political backgrounds among countries. ${ }^{47}$

\section{Supplementary Materials}

The online-only Data Supplement is available with this ar- ticle at https://doi.org/10.4306/pi.2017.14.3.289.

\section{REFERENCES}

1. Gould TD, Manji HK. The molecular medicine revolution and psychiatry: bridging the gap between basic neuroscience research and clinical psychiatry. J Clin Psychiatry 2004;65:598-604.

2. Zarogianni E, Moorhead TW, Lawrie SM. Towards the identification of imaging biomarkers in schizophrenia, using multivariate pattern classification at a single-subject level. Neuroimage Clin 2013;3:279-289.

3. Trifilieff $P$, Martinez D. Imaging addiction: D2 receptors and dopamine signaling in the striatum as biomarkers for impulsivity. Neuropharmacology 2014;76:498-509.

4. Lener MS, Iosifescu DV. In pursuit of neuroimaging biomarkers to guide treatment selection in major depressive disorder: a review of the literature. Ann N Y Acad Sci 2015;1344:50-65.

5. Koob GF, Roberts AJ, Schulteis G, Parsons LH, Heyser CJ, Hyytia P, et al. Neurocircuitry targets in ethanol reward and dependence. Alcohol Clin Exp Res 1998;22:3-9.

6. Falcone M, Smith RM, Chenoweth MJ, Bhattacharjee AK, Kelsoe JR, Tyndale RF, et al. Neuroimaging in psychiatric pharmacogenetics research: the promise and pitfalls. Neuropsychopharmacology 2013; 38:2327-2337.

7. Duka T, Crombag HS, Stephens DN. Experimental medicine in drug addiction: towards behavioral, cognitive and neurobiological biomarkers. J Psychopharmacol 2011;25:1235-1255.

8. Dunlop BW, Mayberg HS. Neuroimaging-based biomarkers for treatment selection in major depressive disorder. Dialogues Clin Neurosci 2014;16:479-490.

9. Ehlis AC, Schneider S, Dresler T, Fallgatter AJ. Application of functional near-infrared spectroscopy in psychiatry. Neuroimage 2014;85:478-488.

10. Yizhar O, Fenno LE, Davidson TJ, Mogri M, Deisseroth K. Optogenetics in neural systems. Neuron 2011;71:9-34.

11. Tomer R, Ye L, Hsueh B, Deisseroth K. Advanced CLARITY for rapid and high-resolution imaging of intact tissues. Nat Protoc 2014;9:16821697.

12. Chung K, Deisseroth K. CLARITY for mapping the nervous system. Nat Methods 2013;10:508-513.

13. Torous J, Stern AP, Padmanabhan JL, Keshavan MS, Perez DL. A proposed solution to integrating cognitive-affective neuroscience and neuropsychiatry in psychiatry residency training: The time is now. Asian J Psychiatr 2015;17:116-121.

14. Lesser I. The ASCP Model Psychopharmacology Curriculum for Psychiatric Residency Programs, Training Directors, and Teachers of Psychopharmacology, 2nd Edition. Am J Geriatr Psychiatry 2003;11:466467.

15. Deligiannidis KM, Girgis RR, Lau A, Balon R, Zisook S. Psychiatry resident/fellow-initiated and -designed multi-modal psychopharmacology curriculum for major depression. Acad Psychiatry 2012;36:414-418.

16. Glick ID, Zisook S, Rapaport MH. Teaching the teacher: a report from the third annual American Society of Clinical Psychopharmacology teaching session. J Clin Psychiatry 2013;74:262-264.

17. Glick ID, Salzman C, Cohen BM, Klein DF, Moutier C, Nasrallah HA, et al. Improving the pedagogy associated with the teaching of psychopharmacology. Acad Psychiatry 2007;31:211-217.

18. Naranjo CA, Shulman RW, Ozdemir V. Development and evaluation of a clinical psychopharmacology educational curriculum. J Clin Pharmacol 1997;37:474-479.

19. Muzyk AJ, White CD, Kinghorn WA, Thrall GC. A psychopharmacology course for psychiatry residents utilizing active-learning and residents-as-teachers to develop life-long learning skills. Acad Psychiatry 2013;37:332-335.

20. Chung JY, Insel TR. Mind the gap: neuroscience literacy and the next generation of psychiatrists. Acad Psychiatry 2014;38:121-123.

21. Ross DA, Travis MJ, Arbuckle MR. The future of psychiatry as clinical 
neuroscience: why not now? JAMA Psychiatry 2015;72:413-414.

22. Ross DA, Rohrbaugh R. Integrating neuroscience in the training of psychiatrists: a patient-centered didactic curriculum based on adult learning principles. Acad Psychiatry 2014;38:154-162.

23. Zisook S, Glick ID, Jefferson JW, Wagner KD, Salzman C, Peselow ED, et al. Teaching psychopharmacology: what works and what doesn't. J Clin Psychopharmacol 2008;28:96-100.

24. Benjamin S, Widge A, Shaw K. Neuropsychiatry and neuroscience milestones for general psychiatry trainees. Acad Psychiatry 2014;38:275-282.

25. Roffman JL, Simon AB, Prasad KM, Truman CJ, Morrison J, Ernst CL. Neuroscience in psychiatry training: how much do residents need to know? Am J Psychiatry 2006;163:919-926.

26. Zisook S, Benjamin S, Balon R, Glick I, Louie A, Moutier C, et al. Alternate methods of teaching psychopharmacology. Acad Psychiatry 2005;29:141-154.

27. The psychiatry milestone project. J Grad Med Educ 2014;6(1 Suppl 1):284-304.

28. Thomas CR, Keepers G. The milestones for general psychiatry residency training. Acad Psychiatry 2014;38:255-260.

29. Cuthbert BN. Research Domain Criteria: toward future psychiatric nosologies. Dialogues Clin Neurosci 2015;17:89-97.

30. Cuthbert BN. Translating intermediate phenotypes to psychopathology: the NIMH Research Domain Criteria. Psychophysiology 2014;51:12051206.

31. Simmons JM, Quinn KJ. The NIMH Research Domain Criteria (RDoC) Project: implications for genetics research. Mamm Genome 2014;25:23-31

32. McCoy TH, Castro VM, Rosenfield HR, Cagan A, Kohane IS, Perlis $\mathrm{RH}$. A clinical perspective on the relevance of research domain criteria in electronic health records. Am J Psychiatry 2015;172:316-320.

33. Insel T, Cuthbert B, Garvey M, Heinssen R, Pine DS, Quinn K, et al. Research domain criteria $(\mathrm{RDoC})$ : toward a new classification framework for research on mental disorders. Am J Psychiatry 2010;167:748-751.

34. Van Amburgh JA, Devlin JW, Kirwin JL, Qualters DM. A tool for measuring active learning in the classroom. Am J Pharm Educ 2007;71:85.
35. Osser DN, Patterson RD, Levitt JJ. Guidelines, algorithms, and evidence-based psychopharmacology training for psychiatric residents. Acad Psychiatry 2005;29:180-186.

36. Mata DA, Ramos MA, Bansal N, Khan R, Guille C, Di Angelantonio E, et al. Prevalence of depression and depressive symptoms among resident physicians: a systematic review and meta-analysis. JAMA 2015; 314:2373-2383.

37. Dunstone DC. A neurosciences-in-psychiatry curriculum project for residents in psychiatry. Acad Psychiatry 2010;34:31-38.

38. Hill AG, Yu TC, Barrow M, Hattie J. A systematic review of residentas-teacher programmes. Med Educ 2009;43:1129-1140.

39. Zandi PP, Judy JT. The promise and reality of pharmacogenetics in psychiatry. Clin Lab Med 2010;30:931-974.

40. Moller HJ, Rujescu D. Pharmacogenetics--genomics and personalized psychiatry. Eur Psychiatry 2010;25:291-293.

41. Malhotra AK, Zhang JP, Lencz T. Pharmacogenetics in psychiatry: translating research into clinical practice. Mol Psychiatry 2012;17:760-769.

42. Aitchison KJ, Malhotra AK. The Ninth Annual Pharmacogenetics in Psychiatry Meeting report. Psychiatr Genet 2011;21:112-113.

43. Bennett JI, Handa K, Mahajan A, Deotale P. Psychiatry chief resident opinions toward basic and clinical neuroscience training and practice. Acad Psychiatry 2014;38:141-144.

44. Glick ID, Zisook S. The challenge of teaching psychopharmacology in the new millennium: the role of curricula. Acad Psychiatry 2005;29:134140.

45. Fung LK, Akil M, Widge A, Roberts LW, Etkin A. Attitudes toward neuroscience education in psychiatry: a national multi-stakeholder survey. Acad Psychiatry 2015;39:139-146.

46. Gopalan P, Azzam PN, Travis MJ, Schlesinger A, Lewis DA. Longitudinal interdisciplinary neuroscience curriculum. Acad Psychiatry 2014;38:163-167.

47. An K, Lee SH, Park E, Sohn I, Lee JH, Lee J, et al. Development of new residency training programs for psychiatry in Korea. J Korean Neuropsychiatr Assoc 2013;52:187-196. 